\title{
Research on Listed Company Financial Management Mode Innovation Trend under the Registration System Background
}

\author{
Pengwen Xiao \\ Guangdong University of Science \& Technology, \\ Dongguan 523083,China
}

\begin{abstract}
In this paper, we conduct theoretical research on the listed company financial management mode innovation trend under the registration system background. Cycles of the core macroeconomic environment is each enterprise that must face the reality of the problem, for the listed companies, the macroeconomic environment is set up financial strategy need to consider problems listed companies must be good at making scientific financial strategy to avoid and reduce the negative influence of the macro-economic changes. Under the condition of the socialist market economy, as the listed company financial management is to maximize the value of the company ultimate goal. Our research combines the registration system background to propose the novel perspective that is meaningful.
\end{abstract}

Keywords- Listed Company, Financial Management, Innovation, Registration System, Mode.

\section{Introduction}

With the continuous development of the securities market, investors are increasingly tend to be more rational, more attention to financial status of modern listed companies. The financial status of listed companies can be reflect through a series of the financial indicators, but the financial index can only reflect the company's business activities in a certain moment, some aspects of the basic situation, but investors and operators comprehensive results that often need to know about the company's financial situation, as the basis of investment decision and management decision [1-2].
According to the literature review, the main quality problems of the listed company financial report information could be summarized as the follows. (1) Current accounting standards for enterprises in basic accounting policy selection gives companies greater flexibility, and companies tend to choose accounting method works best for us, the resulting different results lead to the same financial report do not conform to the requirements of the comparability of data and information, to some extent, this also provides a possible manipulation of the profits for the company. (2) To make the right judgment and decision making, even if is true and reliable financial reporting information as if we provide is not enough in time, but also will lose its timeliness, its effect on information users will also be discounted, or no practical significance. (3) Some of the listed company to achieve its purpose, in the preparation of financial reports is often overstated profits, inflated assets, are forged general financial reporting information, etc., to the enterprise actual financial position, operating results and cash flow status.

The object of the financial management of listed companies is the listed company's cash flow is an effective plan, raise and use of basic funds management. The operation effect and efficiency of listed companies is ultimately reflected through the financial indicators, and therefore, the listed company financial crisis early warning must be the result of the real-time through the financial index to reflect that should obey the listed guidelines. (1) Financial results must be the feedback as soon as possible to the listed company managers at all levels, allow them to quickly response and improve the business and management, to improve performance. (2) All 
the listed companies operate business link must be closely related to finance. (3) Listed companies operating state of all the business process must be real-time, truthfully reflect the general financial condition [3-4].

Capital management mechanism is the effective management of the funds, control and operation mechanism. Budget management is on the basis of the general scientific management forecast and the decision-making, around the enterprise strategic target, for a certain period of enterprise funds to the raise, use and distribution of financial activities such as planning and planning, make the production and operation activities carried out in accordance with the core predetermined plan and plan flow and movement, so as to realize the effective management mechanism, enterprise financial management goal and the inherent requirement of capital operation mechanism is the same.

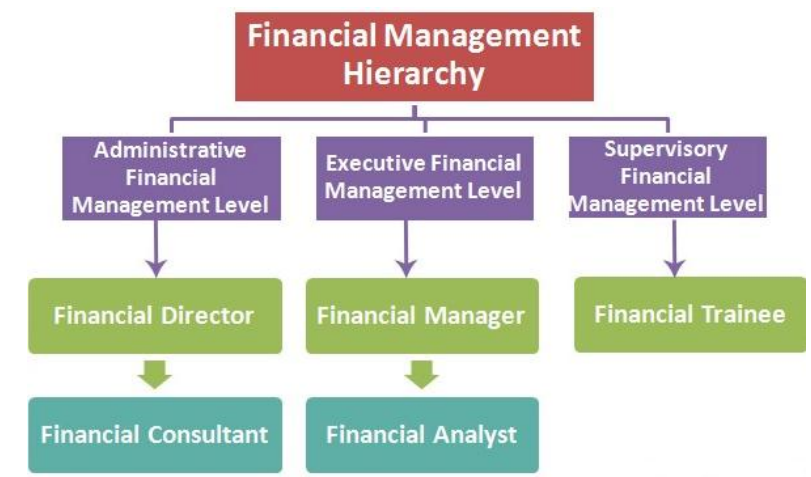

Figure 1. The General Financial Management Architecture

In this paper, we conduct research on listed company financial management mode innovation trend under the registration system background. Enterprise financial budget management is the guarantee of healthy development of the enterprise, but also conforms to the requirement of the modern enterprise development that is an important part of enterprise financial centralized control. The financial budget management of the enterprise, not only affects the economic benefits of enterprises, more is closely related to the vital interests of the employees. To strengthen enterprise financial budget management, can guarantee steadily implement enterprise development strategy, to maximize the enterprise value, and improve enterprise economic benefits. In the later parts, we will analyze in detail.

\section{Our Proposed Methodology}

The China's Securities Market. In the securities market, investors can affect the share price through about future events information to determine whether the prices of the securities are reasonable. The emergence of the information is random and the continuous, investors constantly according to the new information to adjust their expectations, stock prices also constantly changes. Information can be quickly and accurately affect stock price depends on the effectiveness of the securities market. If the information is without prejudice to the way gets fully reflected in the stock price in a timely manner, then the market can be considered to be effective. Market means that the stock market can effectively price for Pointers to guide capital resources effectively configuration, and finally realizes the social resource allocation optimization. So that the research on the effectiveness of the securities market in China has important theoretical and practical significance [5].

The rise of the securities market is a product of the China's economic reform tide that the system construction of the first driving force has always come from the government, the 
played an increasingly important role in fundamental.

Internal control system is refers to the enterprise executive leadership and that each administrative department of the relevant personnel, when dealing with production and business activities of mutual connection and restriction a kind of management system, including to ensure normal to take a series of necessary management measures which the enterprise. Strict accounting management is the focus of the internal control system design of a reasonable and effective organization and post division of labor, implementation of post responsibility and standardization of business processing procedures.

The Registration System Background. Registered production is the direction of the distribution system reform in our country in the future, is from the administrative examination and approval to the distribution system in our country market mechanism is an important step. The registration system is the key to reform the current "shape" authorization, to break the whose regardless of old pattern, the lower the issuance examination power to exchange as a starting point, step by step.

At the same time, according to international practice to review devolution to exchange, procedural, authenticity, and by its form, the securities and futures commission oversees exchange, only in the process when it is necessary to retain veto power. Later as long as the application for listing of basic corporate compliance, reached the threshold of the public, the information disclosure of real and the effective, it should let the listing, as far as possible to return the options market, the investors make their own judgments, in the decision mechanism of listed company to strengthen the basic role of the market mechanism. Authorization can be found that some issuers of fraud and the basic stock issue application have a veto. But the government behavior has its ability to the border, although the stock issuance examination in a large number of manpower and material resources, but it is difficult to do review both accurate, and easy cause power rent-seeking, reduce the audit results. In addition, a public stock offering is subject to government review is approved while investors are prone to rely on the psychological, less independent judgment over the quality of the issuer, so if investors suffer, tend to blame the government. From the issuance examination system analysis, the mature market has formed a multi-level market system, targeting different listing applicants, to develop general different listing standards, provide diversified listed form, to compliance audit of listed company, for the first time to apply for only, by setting the corresponding listing standards continuously, continuously strengthen the protection of the rights and interests of investors, strengthen rights of shareholders, independent directors and audit committee, strengthen the transparency of information disclosure [7].

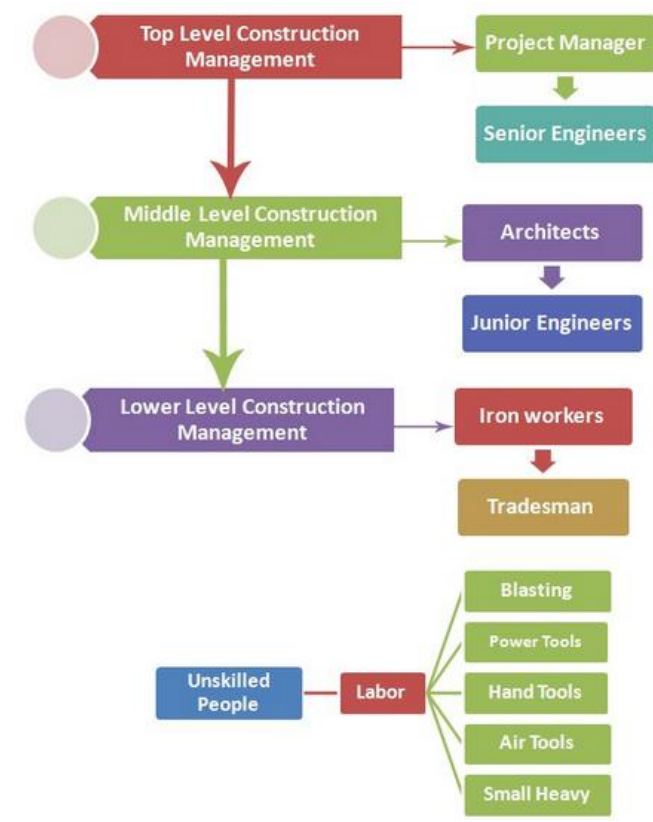

Figure 3. The Registration System and Ordianry Business Management Flowchart

The Financial Budget Management. Enterprise financial budget management is an important part of basic enterprise budget 
management, according to enterprise development strategy and annual business plan production, considering the budget during the period of the economic policy, market environment factors, such as for a certain period of the financial activities of the budget.

In order to ensure the completion of the main indicators, the budget must formulate strict budget analysis and evaluation methods, effectively control the process of budget implementation. Enterprise can according to the results of budget implementation, the implementation of performance appraisal, reasonable with the amount of rewards and punishments. Financial budget examination should have the basis of accurate data, to quantitative assessment index that is reasonable, avoid the arbitrariness. Enterprise group should establish statistical accounting, financial budget management to oversee reflect the completion of each phase of the basic financial budget indicators. By comparing the budget number and the actual number of differences, analyses the reasons and put forward the improvement measures, timely correcting deviation to guarantee the effect of budget management [8].

Through the financial budget management, better treatment of enterprise assets profitability and liquidity, and the relationship between the costs and risks of financial structure, to carry out financial budget plan, or optional breakthrough financial budget and the basic financial risk, to take preventive measures, early reasonable risk coping strategies, effectively avoid the financial risk, achieve business objectives to provide powerful guarantee for the basic enterprise. Financial budget management as an important management tool is one of the modern enterprises is playing an increasingly important role that is the need of enterprise management innovation, is the modern enterprise financial management needs to solve an important issue. Therefore, strengthening the financial budget management of the enterprise, can achieve cutbacks, so as to improve corporate assets to improve the economic benefit.

\section{Conclusion}

In this paper, we conduct research on listed company financial management mode innovation trend under the registration system background. Under condition of market economy, the listed company financial supervision level decides the production and operation scale and the market competition ability, financial regulation should be the core of the management of listed companies. Build internal financial supervision system of listed companies, both is advantageous to the basic operators realize investors set financial goals, but also to maintain the interests of the other main stakeholders. Operator is the comprehensive implementation main work efficiency of internal financial control, improve the efficiency of financial resources and comprehensive utilization, operator to improve comprehensive utilization efficiency of financial resources in the process of need to weigh the management risk, the financial risk, investment risk, work to avoid errors caused by accidental damage.

\section{References}

[1] Haque, Tobias Akhtar, David Knight, and Dinuk Jayasuriya. "Capacity constraints and public financial management in small Pacific Island countries." Asia \& the Pacific Policy Studies 2.3 (2015): 609-622.

[2] Zhou, Yudi, and Rong Fu. "Analysis of Hot-Topics and Prospect for Study on Theory of Financial Management in China." Proceedings of the 21st International Conference on Industrial Engineering and Engineering Management 2014. Atlantis Press, 2015.

[3] GAUDECKER, HANS, and MARTIN VON. "How does household portfolio diversification vary with financial literacy 
and financial advice?." The Journal of Finance 70.2 (2015): 489-507.

[4] Khwannimit, Bodin, and Rungsun Bhurayanontachai. "The direct costs of intensive care management and risk factors for financial burden of patients with severe sepsis and septic shock." Journal of critical care 30.5 (2015): 929-934.

[5] Gomulya, David, and Warren Boeker. "Reassessing board member allegiance: CEO replacement following financial misconduct." Strategic Management Journal (2015).

[6] Chan, James L. "New development: China promotes government financial accounting and management accounting." Public Money \& Management 35.6 (2015): 451-454.

[7] Martin, Kelly D., and Ronald Paul Hill. "Saving and Well-Being at the Base of the Pyramid Implications for Transformative Financial Services Delivery." Journal of Service Research (2015): 1094670514563496.

[8] Carboy, Jaimie. "Workforce Engagement and the Financial Opportunity Center Model: A Qualitative Evaluation of Client Outcomes in Chicago." Society for Social Work and Research 19th Annual Conference: The Social and Behavioral Importance of Increased Longevity. Sswr, 2015. 